\title{
A comparison of the bilateral decompression via unilateral approach versus conventional approach transforaminal lumbar interbody fusion for the treatment of lumbar degenerative disc disease in the elderly
}

Yifan Huang ${ }^{\dagger}$, Jian Chen ${ }^{\dagger}$, Peng Gao, Changjiang Gu, Jin Fan, Zhiyi Hu, Xiaojian Cao, Guoyong Yin ${ }^{*}$ and Wei Zhou*

\begin{abstract}
Background: Bilateral decompression via unilateral approach (BDUA) is an effective surgical approach for treating lumbar degenerative diseases. However, no studies of prognosis, especially the recovery of the soft tissue, have reported using BDUA in an elderly population. The aims of these research were to investigate the early efficacy of the bilateral decompression via unilateral approach versus conventional approach transforaminal lumbar interbody fusion (TLIF) for the treatment of lumbar degenerative disc disease in the patients over 65 years of age, especially in the perioperative factors and the recovery of the soft tissue.

Methods: The clinical data from 61 aging patients with lumbar degenerative disease who received surgical treatment were retrospectively analyzed. 31 cases who received the lumbar interbody fusion surgery with bilateral decompression via unilateral approach (BDUA) were compared with 30 cases who received conventional approach transforaminal lumbar interbody fusion. The radiographic parameters were measured using X-ray including lumbar lordosis angle and fusion rate. Japanese Orthopedic Association (JOA), Visual Analogue Scale (VAS) and Oswestry Disability Index (ODI) scores were used to evaluate the clinical outcomes at different time points. Fatty degeneration ratio and area of muscle/vertebral body were used to detect recovery of soft tissue.

\footnotetext{
*Correspondence: guoyong_yin@sina.com; zwjsph@sina.com

${ }^{\dagger}$ Yifan Huang and Jian Chen contributed equally to this work.

Department of Orthopedics, The First Affiliated Hospital of Nanjing Medical University, No. 300 Guangzhou Road, Nanjing 210029, People's Republic of China
}

(c) The Author(s). 2021 Open Access This article is licensed under a Creative Commons Attribution 4.0 International License, which permits use, sharing, adaptation, distribution and reproduction in any medium or format, as long as you give appropriate credit to the original author(s) and the source, provide a link to the Creative Commons licence, and indicate if changes were made. The images or other third party material in this article are included in the article's Creative Commons licence, unless indicated otherwise in a credit line to the material. If material is not included in the article's Creative Commons licence and your intended use is not permitted by statutory regulation or exceeds the permitted use, you will need to obtain permission directly from the copyright holder. To view a copy of this licence, visit http://creativecommons.org/licenses/by/4.0/. The Creative Commons Public Domain Dedication waiver (http://creativecommons.org/publicdomain/zero/1.0/) applies to the data made available in this article, unless otherwise stated in a credit line to the data. 


\begin{abstract}
(Continued from previous page)
Results: The BDUA approach group was found to have significantly less intraoperative blood loss $(p<0.05)$ and postoperative drainage $(p<0.05)$ compared to conventional approach transforaminal lumbar interbody fusion group. Symptoms of spinal canal stenosis and nerve compression were significantly relieved postoperatively, as compared with the preoperative state. However, the opposite side had a lower rate of fatty degeneration $(9.42 \pm 3.17 \%)$ comparing to decompression side $(11.68 \pm 3.08 \%)(P<0.05)$ six months after surgery in the BDUA group. While there were no significant differences $(P>0.05)$ in two sides of conventional transforaminal lumbar interbody fusion approach group six months after surgery.

Conclusions: Bilateral decompression via unilateral approach (BDUA) is able to reduce the intraoperative and postoperative body fluid loss in the elderly. The opposite side of decompression in BDUA shows less fatty degeneration in 6 months, which indicates better recovery of the soft tissue of the aging patients.
\end{abstract}

Keywords: Bilateral decompression via unilateral approach, Lumbar degenerative disease, Fatty degeneration

\section{Background}

Lumbar degenerative diseases are the most common spinal diseases in the aging population and are increasing in worldwide; among these diseases, lumbar degenerative disc disease is especially common. Between 2000 and 2009, 380, 305 patients were diagnosed and underwent surgery, and the number of cases increased 2.4-fold in the United States [1]. The multifidus muscles, located on either side of the spinous processes, play an important role in stabilizing the joints within the spine [2]. Recent research has shown that among the paraspinal muscles, the multifidus muscle is associated with facet joint osteoarthritis, spondylolisthesis, and disc narrowing [3]. Imaging indicates that these diseases cause a decrease in muscle size and radiographic density, and an increase in fat deposits [4]. Recent research has shown that degeneration of the paraspinal muscles, especially the left muscle, are correlated with age [5]. The paraspinal muscles may also be replaced with fat in people with lumbar degenerative disease [6], and this replacement may be aggravated postoperatively [7]. In patients undergoing posterior lumbar interbody fusions, smaller area of the paraspinal muscles were associated with less fusion time [8]. In lumbar intervertebral disc surgery, bilateral decompression via a unilateral approach [9] (BDUA) has better results in terms of reducing the operation time, blood loss and other complications. However, no studies of prognosis, especially the recovery of the soft tissue, have reported using BDUA in an elderly population, such as in those over the age of 65. In addition, few studies have investigated postoperative multifidus muscle changes, particularly fatty degeneration. This study retrospectively analyzed $61 \mathrm{pa}-$ tients who received lumbar fusion between January 2016 and April 2018, and compared BDUA and conventional approach transforaminal lumbar interbody fusion.

\section{Methods}

This retrospective case-control study was performed analyzing 61 aging patients with lumbar degenerative disease.

\section{Patient data}

The inclusion criteria were as follows: 1 . Single-segment degenerative disc herniation and spinal canal stenosis with neurological symptoms. 2. Age over 65 years. 3 . More than one radiographic examination(X-ray, computed tomography $(\mathrm{CT})$, Magnetic Resonance Imaging.

(MRI) or Diffusion tensor imaging (DTI))confirming nerve root compression. 4. Good general condition: blood pressure after intervention $<160 \mathrm{mmHg}$ systolic and $<100$ $\mathrm{mmHg}$ diastolic [10]; intraoperative blood glucose levels < $10 \mathrm{mmol} / \mathrm{l}$ (The Society for Ambulatory Anesthesia) [11]. Cardiopulmonary function, assessed by the anesthesiologist, is able to tolerate general anesthesia.

The exclusion criteria were as follows: 1 . More than one segmental disc herniation. 2. Lumbago and no clear nerve root symptoms. 3. Advanced age (over 95 years). 4 . Tumors. 5. Serious postoperative complications.6. morbid obesity. 7. Systemic disease or ane insufficiency.

Lumbar disc herniation was combined with stenosis in L4/5 in 47 patients, L3/4 in 3 patients and L5/S1 in 11 patients. Group A received bilateral decompression via a unilateral approach surgery, and group B received conventional transforaminal lumbar interbody fusion approach. All patients underwent lumbar X-ray, threedimensional CT, and magnetic resonance imaging (MRI) before surgery. After surgery, all patients were followed up for 26.2 months, with a range of 20-36 months.

\section{Surgical methods \\ Bilateral decompression via unilateral approach (BDUA) group}

Each patient was placed in prone position and intubated under general anesthesia. A paravertebral incision was made in the lesion intervertebral space. The paravertebral muscle space was obtusely separated, With the help of mini-retractor designed by ourselves [12], multifidus and the longissimus muscles were separated and the pedicle entry point was exposed clearly (Fig. 1a,b,c). The pedicle screw was inserted into the target vertebra, and 


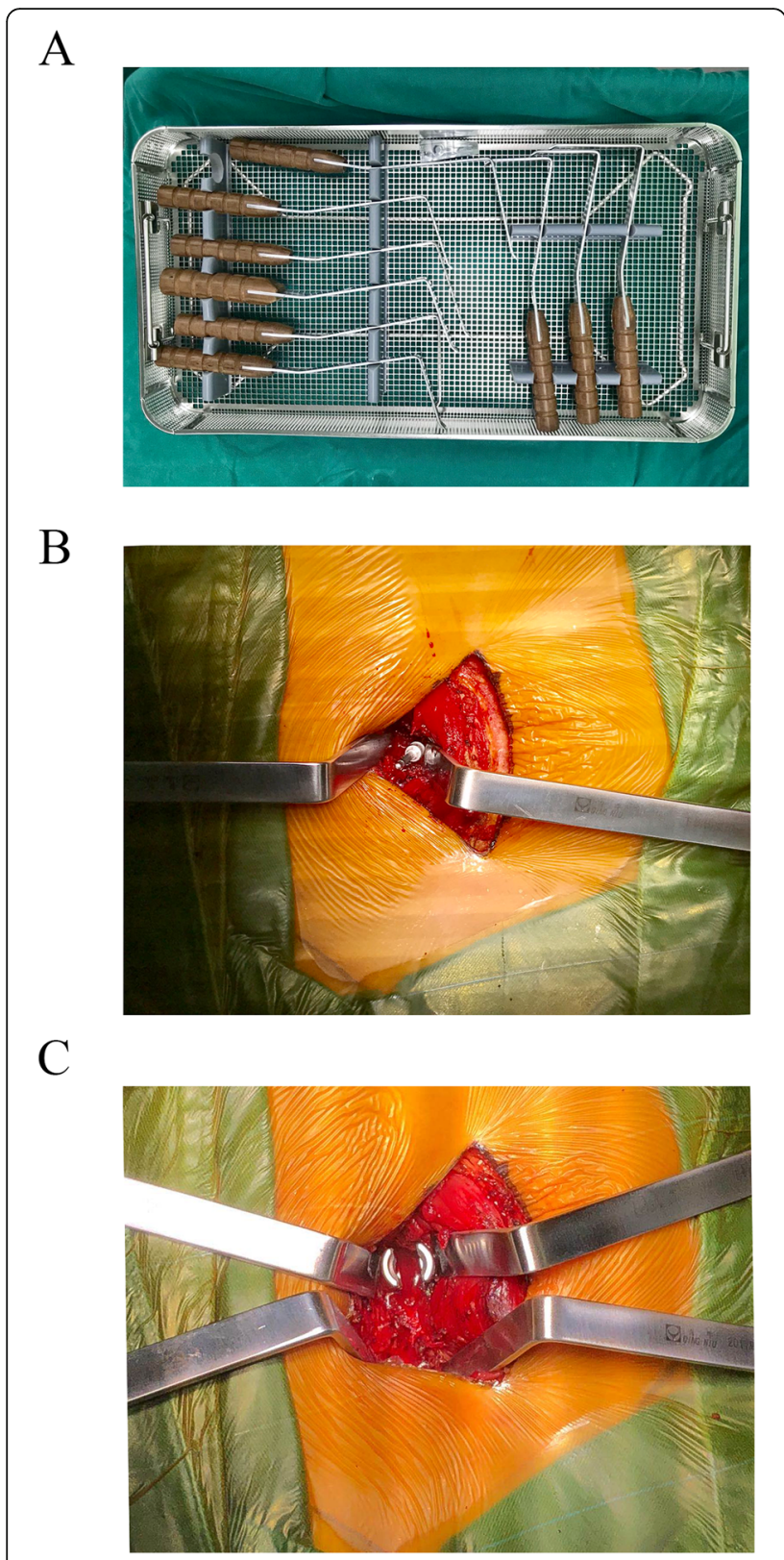

Fig. 1 The exposure of the pedicle entry point through the Wiltse's approach. a: The self-designed mini-retractor b\&c: Intraoperative usage of the self-designed mini-retractor and the exposion of pedicle entry point

the articular process was removed with bone biting forceps. The vertebral plate after c-arm X-ray fluoroscopy confirmed that the reduction was satisfactory. During this process, the nerve root and dural sac were protected. Then the inferior facet and approximately $1 / 3$ of the superior facet of symptomatic side were removed, the spinal canal was exposed, and the upper and lower laminar margins were removed depending on the specific conditions of spinal stenosis. Then the ipsilateral ligamentum flavum was completely removed. The contralateral view were obtained by tilting the operating table. Resection of the contralateral junction of lamina with the spinous process was performed in order to expanded spinal canal. At this point, the contralateral ligamentum flavum was excised. The soft tissue and osteophytes of the contralateral subarticular zone was excised to decompress the contralateral nerve root. Meanwhile, the protruded nucleus was removed, the intervertebral space was opened, and the cartilage of the vertebral endplate was removed for use in the bone graft fusion. The extracted articular process and lamina were used for granular packing in the intervertebral space, and the cancellous bone was compressed and placed into the intervertebral fusion cage. Wiltse's approach was used to implant a contralateral pedicle screw. Finally, the incision was sutured after a negative pressure flow tube was placed. Fig. 2a,c shows an intraoperative photographs and schematic diagram of this surgical approach [13].

\section{Control group: conventional approach transforaminal lumbar interbody fusion}

Each patient was placed in prone position and intubated under general anesthesia. A standard midline incision and subperiosteal exposure is made out to the tips of the transverse processes and the longissimus and multifidus are separated from the posterolateral gutter. The pedicle screws were placed into the upper and lower vertebral bodies. The spinous process and bilateral lamina and ligaments were removed with bone biting forceps, whereas the ligamentum flavum and the medial edge of the articular process were removed according to the specific conditions of the disease. The nerve root canal and lateral crypt were expanded, and the dural sac and nerve root were protected intraoperatively. Then the annulus fibrosus was cut open, the nucleus pulposus was removed, upper and lower cartilage endplates were removed, and autologous bone particles were implanted between the vertebral bodies. The dural sac and nerve roots were then explored. Finally, the incision was sutured after a negative pressure flow tube was placed. Figure $2 b, d$ shows a schematic diagram and intraoperative photographs of this surgical approach.

\section{Postoperative management}

All patients in the two groups had the drainage tube removed within $72 \mathrm{~h}$ and rested in bed for 3 days. Then, they were allowed to ambulate with the assistance of a lumbar brace within at least the next six weeks. All patients were followed up every three months, and X-ray, CT scans were reviewed. Besides,MRI were followed up in 3 and 6 months. 

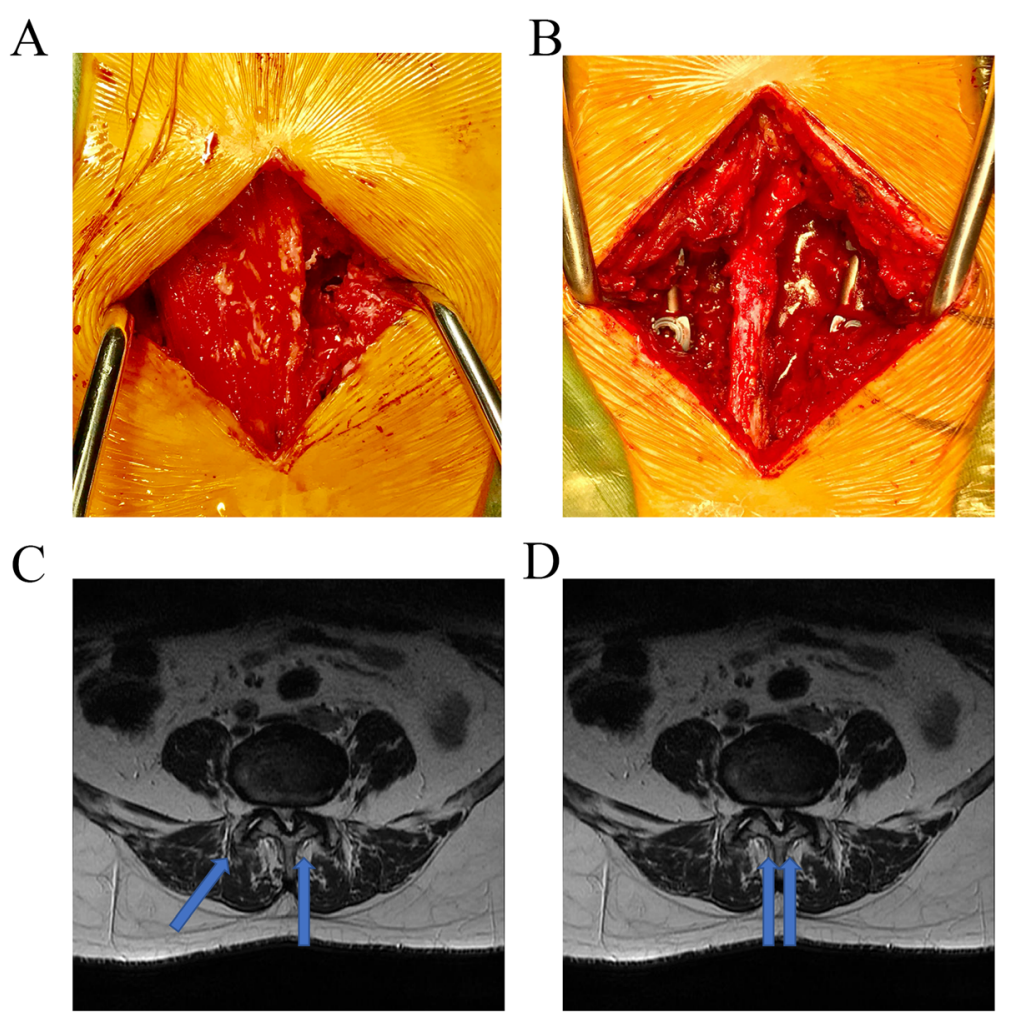

Fig. 2 Schematic diagram and intraoperative photographs of the lumbar fusion operation. a $\& \mathbf{c}$ : Intraoperative photographs(a) and schematic diagram(c) of bilateral decompression via unilateral approach; $\mathbf{b} \& \mathbf{d}$ :Intraoperative photographs(b) and schematic diagram(d) of conventional approach transforaminal lumbar interbody fusion

\section{Clinical and radiological assessment}

All patients were assessed with Japanese Orthopedic Association (JOA), Visual Analogue Scale (VAS) and Oswestry Disability Index (ODI) scores before and after surgery. In addition, all patients were followed up every 3 months after surgery with X-ray, CT of the lumbar spine. MRI were followed up in 3 and 6 months. X-ray and CT were used to calculate the lumbar spine fusion rate through Lee's radiographic criteria $[14,15]$. X-ray was also used to measure L1-S1 lumbar lordosis of the standing position [16] (Fig. 3a, b). As shown in Fig. 4a,b, MRI was used to detect the fatty degeneration and muscle/vertebral body ratio [17]. VB represents the vertebral body size, CSA represents the cross-sectional area, and SC indicates subcutaneous fat. The calculation of the muscle/vertebral body ratio is also based on the cross-sectional area (CSA) and the vertebral body size (VB). The cross-sectional areas of the vertebral body and paraspinal muscles were outlined and measured by authors using Image J software (National Institutes of Health, MD, USA). Due to the cross-sectional area of the vertebral body would hardly change, the ratio of muscle/vertebral body can reflect the atrophy of paravertebral muscle. The gray-scale range of the CSA and SC areas was also analyzed in Image J software, as shown in
Fig. 4c, d. The grayscale value of the CSA region overlap with the SC region (Fig. 4e) was used as an index of fatty degeneration of the multifidus muscle. In addition, the CSA/VB ratio indicated the degree of multifidus muscle atrophy. The surrounding layers of the lumbar fusion area were chosen to avoid metal interference. In order to unify the standard, the upper edge layer (inferior vertebral endplate) of the intervertebral disc in the upper segment of the fusion segment were selcected for the measurement.

\section{Statistical analysis}

All data were analyzed in SPSS 22.0 software (IBM Corporation, NY, USA) and are presented as mean \pm standard deviation. Differences between groups were tested by unpaired $t$ test or Man-Whitney $U$ test. Categorical variables were compared via chi-square test or Fisher exact test. Paired $t$ test was used to compare affected side and opposite side within groups. A $P$-value of $<0.05$ was considered statistically significant.

\section{Results}

Perioperative conditions

All 61 patients received the BDUA approach or conventional approach transforaminal lumbar interbody fusion 
A

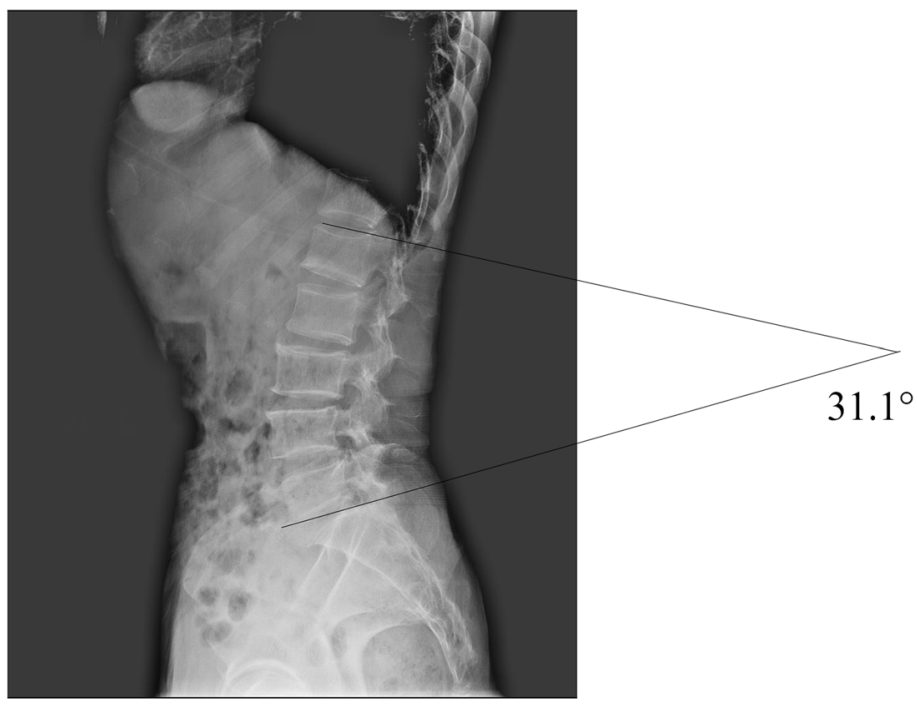

B

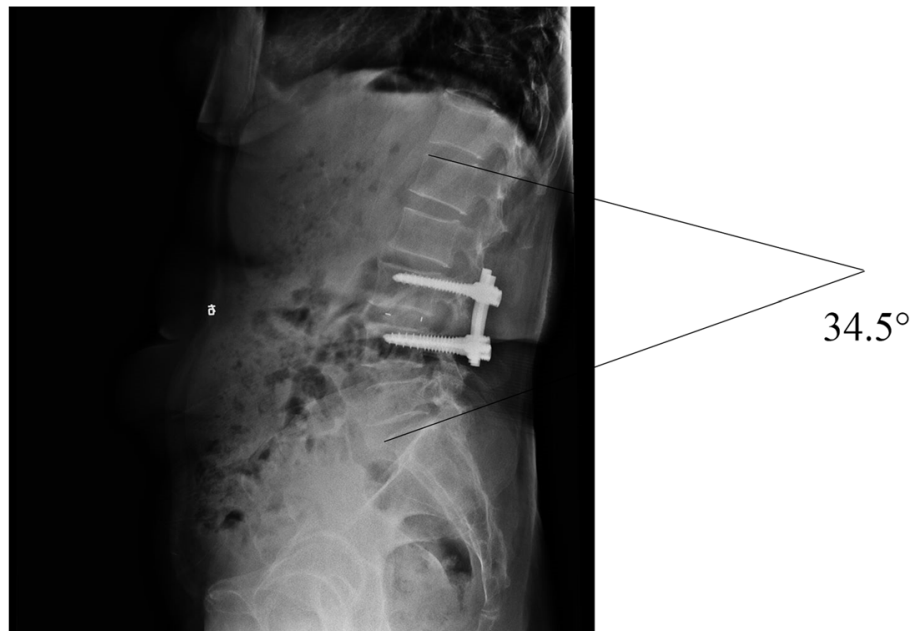

Fig. 3 Mesurement of the L1-S1 lumbar lordosis, a: preoperative lumbar lordosis b: postoperativeb lumbar lordosis

under general anesthesia. All operations were performed successfully without any injury to the nerve root. After the operation, no serious complications such as deep infection, nerve injury, cerebrospinal fluid leakage, deep venous thrombosis or pulmonary infection occurred. The vacuum drainage was removed within three days postoperatively, and all patients were discharged three to four days after the operation. Symptoms of spinal canal stenosis and nerve compression were significantly relieved postoperatively, as compared with the preoperative state.

\section{Clinical and radiological results}

The general data are shown in Table 1, including sex, age, BMI, high blood pressure, diabetes and the segment of the herniated disc. These factors were not significantly different $(P>0.05)$, thus excluding the influence of general factors on the results.
The average operation time for the BDUA group was $2.61 \pm 0.78 \mathrm{~h}$, whereas that of the conventional approach group was $2.85 \pm 0.68 \mathrm{~h}$. The operation times were not significantly different $(\mathrm{P}>0.05)$. However, the BDUA group had the advantage of significantly less $(P<0.01)$ intraoperative blood loss $(153.9 \pm 102.9 \mathrm{ml})$ compared to the conventional approach group $(251.7 \pm 156.1 \mathrm{ml})$. In addition, wound drainage was significantly $\operatorname{reduced}(P<$ $0.0001)$ in the BDUA group $(178.4 \pm 86.7 \mathrm{ml})$, compared with the conventional approach group $(359.8 \pm 179.2$ $\mathrm{ml})$. The lengths of hospital stays between two groups has no significant difference (Table 2). Clinical outcomes are shown in Table 3, including the VAS, ODI and JOA scores. Most of the scores between two groups were not significantly different. However, the VAS score of the BDUA group three months after operation was $1.33 \pm$ 0.48 , whereas that of the control group was $3.45 \pm 0.43$. This result suggests that patients in the BDUA group 


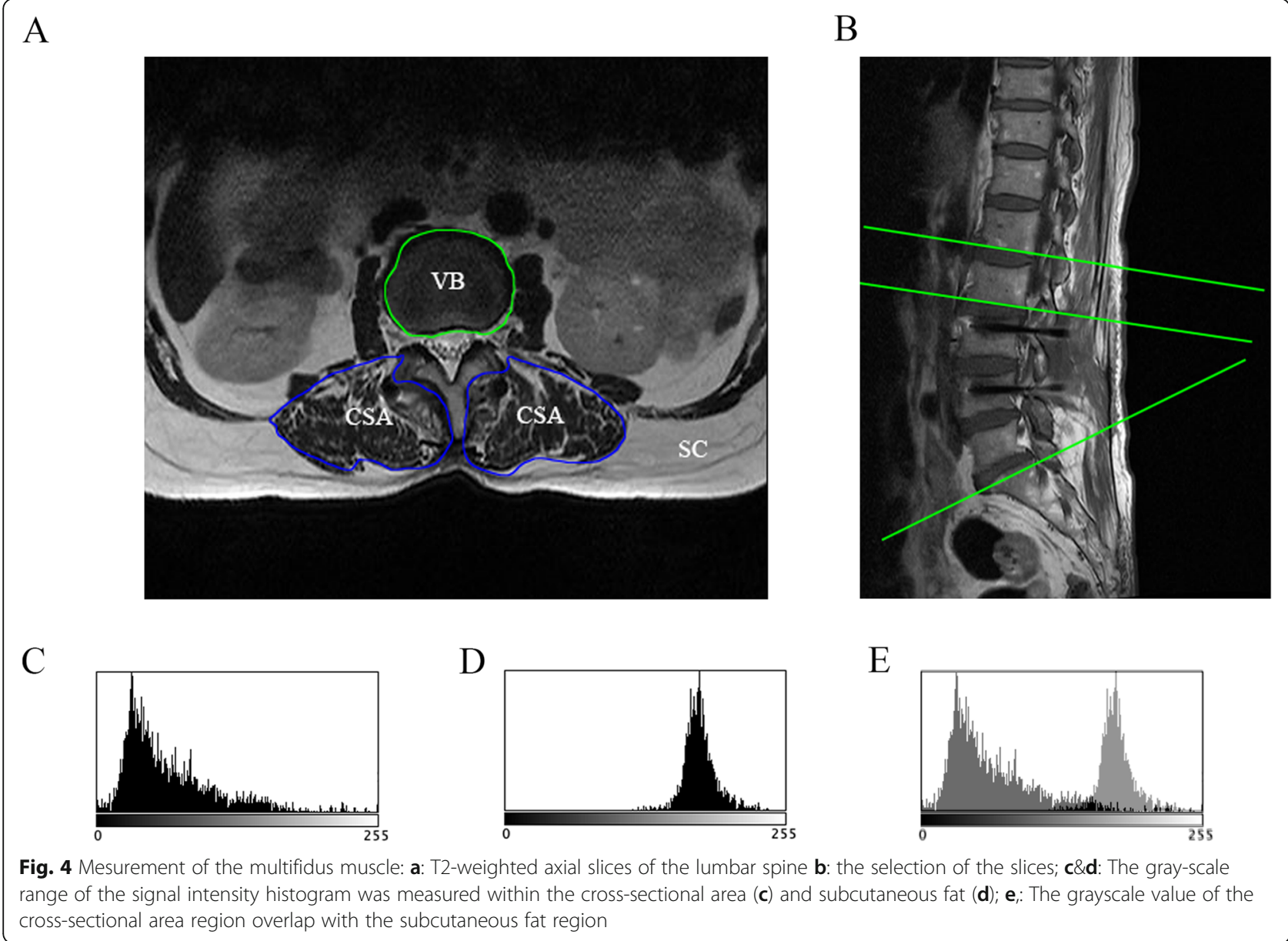

Table 1 Descriptive data and disease characteristics of patients

\begin{tabular}{|c|c|c|c|c|}
\hline Variable & BDUA & Control & P-Value & Significance \\
\hline Sex & & & $0.3004^{*}$ & $\mathrm{~ns}$ \\
\hline Male & 16 & 20 & & \\
\hline Female & 15 & 10 & & \\
\hline Age & $72.26 \pm 3.43$ & $71.33 \pm 3.41$ & 0.2956 & ns \\
\hline $65-70$ & 6 & 10 & & \\
\hline $70-75$ & 14 & 14 & & \\
\hline over 75 & 11 & 6 & & \\
\hline BMI & $24.85 \pm 2.93$ & $24.87 \pm 2.10$ & 0.9875 & ns \\
\hline High blood pressure & 11 & 6 & $0.2546^{*}$ & ns \\
\hline diabetes & 4 & 5 & $0.7315^{*}$ & ns \\
\hline Segment of herniated disc & & & $0.8068^{*}$ & ns \\
\hline$\llcorner 3 / 4$ & 1 & 2 & & \\
\hline$\llcorner 4 / 5$ & 24 & 23 & & \\
\hline L5/S1 & 6 & 5 & & \\
\hline
\end{tabular}

Note: Data shown as number or mean \pm standard deviation. $\mathrm{P}<0.05$, significant difference ${ }^{*} x^{2}$ test. Otherwise, independent samples $t$ test BMI, Body Mass Index 
Table 2 Perioperative Factors and Postoperative Outcomes

\begin{tabular}{|c|c|c|c|c|}
\hline Variable & BDUA & Control & P-Value & Significance \\
\hline Operation time & $2.61 \pm 0.78$ & $2.85 \pm 0.68$ & 0.2132 & ns \\
\hline Intraoperative blood loss & $153.9 \pm 102.9$ & $251.7 \pm 156.1$ & 0.0059 & $* *$ \\
\hline Drainage & $178.4 \pm 86.7$ & $359.8 \pm 179.2$ & $<0.0001$ & $* * * *$ \\
\hline Days of hospital stay & $10.35 \pm 3.49$ & $12.07 \pm 3.59$ & 0.0642 & ns \\
\hline Complications cases & 3 & 2 & $0.94^{*}$ & ns \\
\hline \multicolumn{5}{|l|}{ Side of fusion } \\
\hline Both & 0 & 30 & & \\
\hline Left side & 13 & 0 & & \\
\hline Right side & 18 & 0 & & \\
\hline
\end{tabular}

Note: Data shown as number or mean \pm standard deviation. $\mathrm{P}<0.05$, significant difference

${ }^{*} X^{2}$ test. Otherwise, independent samples $t$ test

had less pain in the early stages after surgery. However, at the last follow-up time, both groups showed significant pain relief. As shown Table 4, the fusion rate and lumbar lordosis between the groups were not significantly different $(P>0.05)$. MRI was performed to detect recovery of soft tissue (Table 5 ). We chose the surrounding layers to avoid metal interference. Both the fatty degeneration ratio and area of muscle/vertebral body were not significantly different $(\mathrm{P}>0.05)$ preoperatively. However, the affected side had a higher rate of fatty degeneration six months after surgery in the BDUA group, thus indicating differences in postoperative recovery.

\section{Discussion}

Age is the most significant factor in lumbar degenerative disease, in both the osseous structures and soft tissues. In osseous structures, the vertebral height and disc height are influenced the most. However, the relationship between age and lumbar disc height remains controversial. Khan [5] has found that disc heights, especially those of the L3 segment and L2/L3 disc, are influenced by aging, whereas Bach, by using CT scans, has found no significant difference between middle-aged and elderly people. Variation in disc height is determined much more by sex than by age. However, recent research has clearly indicated that aging is related to the

Table 3 The VAS,ODI and JOA scores of patients at different time points

\begin{tabular}{|c|c|c|c|c|c|}
\hline Variable & & BDUA & Control & P-Value & Significance \\
\hline \multirow[t]{3}{*}{ VAS scores } & post-surgery & $3.45 \pm 0.89$ & $3.07 \pm 1.15$ & 0.1464 & ns \\
\hline & 3 months & $1.33 \pm 0.48$ & $3.45 \pm 0.43$ & $<0.0001$ & $* * * *$ \\
\hline & Last time & $1.25 \pm 0.51$ & $1.40 \pm 0.62$ & 0.3345 & ns \\
\hline \multirow[t]{3}{*}{ ODI scores } & post-surgery & $43.48 \pm 19.30$ & $40.52 \pm 15.53$ & 0.4158 & ns \\
\hline & 3 months & $9.74 \pm 6.71$ & $10.33 \pm 6.54$ & 0.7287 & ns \\
\hline & Last time & & & & \\
\hline \multirow[t]{3}{*}{ JOA scores } & post-surgery & $15.97 \pm 5.12$ & $17.13 \pm 4.12$ & 0.3507 & ns \\
\hline & 3 months & $24.90 \pm 2.33$ & $25.17 \pm 1.82$ & 0.6252 & ns \\
\hline & Last time & $27.87 \pm 2.40$ & $28.27 \pm 1.82$ & 0.2777 & ns \\
\hline \multirow[t]{4}{*}{3 months } & JOA improvement $\geq 75 \%$ & 13 & 11 & & \\
\hline & $\mathrm{JOA}$ improvement $=50-74 \%$ & 12 & 12 & & \\
\hline & JOA improvement $=25-49 \%$ & 5 & 5 & & \\
\hline & JOA improvement $\leq 24 \%$ & 1 & 2 & & \\
\hline \multirow[t]{4}{*}{ Last time } & JOA improvement $\geq 75 \%$ & 26 & 28 & & \\
\hline & $\mathrm{JOA}$ improvement $=50-74 \%$ & 4 & 1 & & \\
\hline & JOA improvement $=25-49 \%$ & 1 & 1 & & \\
\hline & JOA improvement $\leq 24 \%$ & 0 & 0 & & \\
\hline
\end{tabular}

Note: Data shown as number or mean \pm standard deviation. $\mathrm{P}<0.05$, significant difference. Independent samples $t$ test VAS, visual analog scale; ODI, oswestry disability index; JOA, Japanese Orthopaedic Association 
Table 4 Radiologic assessments of patients at postoperation and follow-up

\begin{tabular}{|c|c|c|c|c|}
\hline Variable & BDUA & Control & P-value & Significance \\
\hline Fusion rate (\% of patients) & & & 0.8814 & ns \\
\hline 3 months & 83.8 & 93.3 & & \\
\hline 6 months & 96.8 & 100 & & \\
\hline last time & 100 & 100 & & \\
\hline \multicolumn{5}{|l|}{ Lumbar lordosis } \\
\hline 3 months & $44.79 \pm 8.15$ & $46.30 \pm 8.32$ & 0.4797 & ns \\
\hline Last time & $48.60 \pm 7.61$ & $51.50 \pm 3.35$ & 0.0606 & ns \\
\hline
\end{tabular}

Note: Data shown as number or mean \pm standard deviation. $\mathrm{P}<0.05$, significant difference

Independent samples t test

loss of lumbar curvature [18], fatty infiltration in the lumbar paravertebral muscles [19], and loss of extensor muscle strength [20]. With increasing age, the lumbar muscle fat content changes [21] and causes degeneration of the lumbar spine. Yanik also found a significantly higher fatty degeneration in the paravertebral muscle in patients with low back pain by using the chemical shift MRI [22]. In addition, the occurrence of low back pain after prolonged bed-rest can lead to the atrophy of the paravertebral muscle [23]. However,the paravertebral muscles, especially the multifidus muscles, are influenced the most during the operation [24]. In this study we found that fatty degeneration occurred in the surrounding muscles after fusion surgery. It is reported that due to the loss of tendon adhesion to bone, a decrease in the length and number, myofibrinolysis and degeneration would happen in the muscle bars. Adipose tissue would accumulate in the muscle bundle, outside and inside the muscle [25]. Although we did not find significant postoperative atrophy of paravertebral muscle, BDUA surgery may cause less fatty degeneration due to the less destruction of muscle structure. Hildebrand found that increased severity of fat infiltration in the lumbar multifidus muscles correlated significantly with decreased range of motion of lumbar flexion [26]. The less muscle damage on the BDUA side, may also be helpful for postoperative recovery of motion of lumbar flexion. Thus, protecting the paravertebral muscles from the fatty degeneration may be a favorable option to improve the prognosis of aging patients.

TLIF, the most common approach in lumbar fusion surgery, was first proposed by Harms in 1982 [27]. All degenerative diseases, including degenerative disc disease, disc herniation and spinal canal stenosis, are indications for the TLIF approach. However, TLIF may lead to significant paraspinal muscle injury because of the incision of the lumbar multifidus [28]. Therefore, we used the intermuscular space between the paraspinal muscles. BDUA, first proposed by Young [29], decreases pressure on the side with greater symptoms (including the joints, joint resection, and enlarged nerve root canal and vertebral canal) and involves fusion through intervertebral bone grafting. The treatment limits damage to the spinal rear structure and maximizes retention of structures and ligaments of the posterior components. In addition, the operation reduces the postoperative incidence of low

Table 5 Fatty degeneration ratio and lumbar muscularity of the paraspinal muscles of two groups using MRI

\begin{tabular}{|c|c|c|c|c|c|c|c|c|}
\hline \multirow{2}{*}{$\begin{array}{l}\text { Variable } \\
\text { Fatty degeneration ratio \% }\end{array}$} & \multicolumn{3}{|l|}{ BDUA } & \multicolumn{3}{|l|}{ Control } & \multirow[t]{2}{*}{ p-value } & \multirow[t]{2}{*}{ Significance } \\
\hline & preoperative & 6 month & Change (\%) & preoperative & 6 month & Change (\%) & & \\
\hline Affected side & $7.96 \pm 2.86$ & $11.68 \pm 3.08$ & $2.69 \pm 2.24$ & $8.59 \pm 3.77$ & $11.38 \pm 4.60$ & $2.79 \pm 4.57$ & 0.9601 & ns \\
\hline opposite side & $8.93 \pm 3.48$ & $9.42 \pm 3.17$ & $1.46 \pm 2.80$ & $8.89 \pm 3.23$ & $12.97 \pm 4.58$ & $4.09 \pm 5.05$ & 0.0143 & * \\
\hline$p$-value & 0.2893 & 0.006 & & 0.7472 & 0.1845 & & & \\
\hline Significance & ns & $* *$ & & ns & ns & & & \\
\hline \multicolumn{9}{|c|}{ Area of muscle/vertebral body \% } \\
\hline Affected side & $137.9 \pm 37.2$ & $142.3 \pm 45.1$ & $4.5 \pm 7.9$ & $135.7 \pm 16.1$ & $149.9 \pm 44.7$ & $1.09 \pm 11.4$ & 0.1781 & ns \\
\hline Opposite side & $149.4 \pm 36.0$ & $150.9 \pm 39.9$ & $1.5 \pm 16.1$ & $136.8 \pm 37.3$ & $145.7 \pm 36.8$ & $-4.11 \pm 13.7$ & 0.1039 & ns \\
\hline$p$-value & 0.1487 & 0.3536 & & 0.1685 & 0.3502 & & & \\
\hline Significance & ns & ns & & ns & ns & & & \\
\hline
\end{tabular}

Note: Data shown as number or mean \pm standard deviation. $\mathrm{P}<0.05$, significant difference Independent samples $t$ test 
back pain and maintains the stability of the spine. On the milder side, we used the Wiltse approach to avoid injury from muscle dissection. This approach, first reported by Wiltse [30], uses the clearance between the multifidus and latissimus muscles to access the vertebral lamina. Because of the clearance involves connective tissues and avoids vessels and nerves, this approach limits the possibility of vascular injury and neurological impairment [31]. After the operation, the lumen can close by itself without drainage; therefore, none of our patients had any drainage on that side. Patients receiving the Wiltse approach had less postoperative drainage. In addition, the multifidus muscles can assist in the patient's lateral position, and the integrity of the multifidus muscles can reduce the postoperative recovery times of patients.

TILF and PLIF, the two common surgical approaches in lumbar fusion surgery, have been modified, and MISTLIF minimally invasive surgical methods have been proposed [32, 33]. MIS-TLIF may be efficient in the treatment of one-level lumbar stenosis [34], especially in obese patients [35]. However, MIS-TLIF is not suitable for degenerative disease with severe spinal stenosis, and grade II or higher spondylolisthesis, PLIF and TLIF cannot be substituted in some patients. BDUA has the advantages of reducing paraspinal muscle injury, operation time,operation expense, blood loss and postoperative bed time; therefore, it is preferred for elderly patients. This approach is also suitable for more than one segment. However, BDUA may not be suitable for patients with a herniated disc on both sides.

There are still several limitations in our study: The follow-up time was too short, with the area of muscle/ vertebral body and the fatty degeneration ratio was only calculated at 6 months, so the long-term follow-up still remains to be done. The gray value was used to calculate the fat infiltration ratio. However, the gray value of edema or inflammation in the paraspinal muscle would have similar to the gray value of fat. Edema or inflammation is reported occurred mainly in the first week postoperatively. So, we chose the MRI of 6 months, the period that fat degeneration will be the most obvious, to avoid the interference of the edema or inflammatory response [36]. No obvious edema or inflammation were found in the follow-up, but the slight edema or inflammatory cannot be excluded. Besides, the effect of fatty degeneration on early postoperative activities were not clearly followed up,and early postoperative activities are helpful in reducing postoperative complications such as pneumonia, lower limb thrombosis. No obvious postoperative complications occurred in the patients of this study yet. So, more cases are needed to figure out the correlation between less fatty degeneration in the BDUA group and postoperative complications.
In conclusion, Bilateral decompression via unilateral approach (BDUA) has the advantage in reducing the intraoperative and postoperative body fluid loss in the elderly and the opposite side of decompression in BDUA shows less fatty degeneration in 6 months. Whereas a long-term advantage could not be shown compared to conventional approach transforaminal lumbar interbody fusion.

\section{Abbreviations \\ CT: computed tomography; MRI: magnetic resonance imaging; VAS: visual analogue scale; ODI: Oswestry Disability Index; BDUA: bilateral fusion; VB: vertebral body; CSA: cross-sectional areal; SC: subcutaneous fat; \\ DTI: Diffusion tensor imaging \\ Acknowledgments \\ The authors thank all colleagues who assisted in this study.}

decompression via unilateral approach; TILF: transforaminal lumbar interbody

\section{Authors' contributions}

$\mathrm{YH}$ and $\mathrm{JC}$ carried out the acquisition and interpretation of data. PG and CG carried out the clinical data collection. JF,ZH and XC carried out the operation and radiological measurements. GY and WZ carried out the design of this study. YH and JC did the revision of the manuscript. All authors have read and approved the final manuscript.

\section{Funding}

This study was supported by grants from the National Natural Science Foundation of China (81772351and 81902211), the Jiangsu Committee of Science and Technology-Social Development Plan (BE20191061). These fundings were used for data collection, analysis and publication of the article.

\section{Availability of data and materials}

The data which analyzed during the study are stored in our hospital system and are available from the corresponding author on reasonable request.

Ethics approval and consent to participate

The study protocol was approved by the Ethics Committee of Jiangsu Provincial Hospital and written informed consent were obtained from all patients.

\section{Consent for publication}

Not applicable.

\section{Competing interests}

The authors declare that they have no competing interests.

Received: 5 June 2020 Accepted: 27 January 2021

Published online: 08 February 2021

\section{References}

1. Yoshihara H, Yoneoka D. National trends in the surgical treatment for lumbar degenerative disc disease: United States, 2000 to 2009. Spine J. 2015;15:265-71.

2. Freeman MD, Woodham MA, Woodham AW. The Role of the Lumbar Multifidus in Chronic Low Back Pain: A Review. PM\&R. 2010:2:142-6.

3. Kalichman L, Hodges P, Li L, Guermazi A, Hunter DJ. Changes in paraspinal muscles and their association with low back pain and spinal degeneration: CT study. Eur Spine J. 2010;19:1136-44.

4. Kalichman L, Carmeli E, Been E. The Association between Imaging Parameters of the Paraspinal Muscles, Spinal Degeneration, and Low Back Pain. BioMed Research International. 2017;2017:1-14.

5. Khan AA, lliescu DD, Sneath RJ, Hutchinson CE, Shah AA. Principal component and factor analysis to study variations in the aging lumbar spine. IEEE J Biomed Health Inform. 2015;19:745-51.

6. Park MS, Moon S-H, Kim T-H, Oh J, Lee S-J, Chang HG, et al. Paraspinal Muscles of Patients with Lumbar Diseases. J Neurol Surg A Cent Eur Neurosurg. 2018;79:323-9. 
7. Fan S, Hu Z, Zhao F, Zhao X, Huang Y, Fang X. Multifidus muscle changes and clinical effects of one-level posterior lumbar interbody fusion: minimally invasive procedure versus conventional open approach. Eur Spine J. 2010; 19:316-24.

8. Choi MK, Kim SB, Park CK, Malla HP, Kim SM. Cross-Sectional Area of the Lumbar Spine Trunk Muscle and Posterior Lumbar Interbody Fusion Rate. Clinical spine surgery. 2017;30:E798-803.

9. Oertel MF, Ryang Y-M, Korinth MC, Gilsbach JM, Rohde V. Long-term results of microsurgical treatment of lumbar spinal stenosis by unilateral laminotomy for bilateral decompression. Neurosurgery. 2006;59:1264-9 discussion 1269-1270.

10. Hartle A, McCormack T, Carlisle J, Anderson S, Pichel A, Beckett N, et al. The measurement of adult blood pressure and management of hypertension before elective surgery. Anaesthesia. 2016;71:326-37.

11. Duggan EW, Carlson K, Umpierrez GE. Perioperative Hyperglycemia Management: An Update. Anesthesiology. 2017;126:547-60

12. Li H, Yang L, Xie H, Yu L, Wei H, Cao X. Surgical outcomes of mini-open Wiltse approach and conventional open approach in patients with singlesegment thoracolumbar fractures without neurologic injury. J Biomed Res. 2015;29:76-82.

13. Cavuşoğlu H, Kaya RA, Türkmenoglu ON, Tuncer C, Colak I, Aydin Y. Midterm outcome after unilateral approach for bilateral decompression of lumbar spinal stenosis: 5-year prospective study. Eur Spine J. 2007;16:213342.

14. Lee JH, Lee J-H, Park J-W, Lee HS. Fusion rates of a morselized local bone graft in polyetheretherketone cages in posterior lumbar interbody fusion by quantitative analysis using consecutive three-dimensional computed tomography scans. Spine J. 2011;11:647-53.

15. Fogel GR, Toohey JS, Neidre A, Brantigan JW. Fusion assessment of posterior lumbar interbody fusion using radiolucent cages: X-ray films and helical computed tomography scans compared with surgical exploration of fusion. Spine J. 2008;8:570-7.

16. Been E, Kalichman L. Lumbar lordosis. Spine J. 2014;14:87-97.

17. Jun HS, Kim JH, Ahn JH, Chang IB, Song JH, Kim TH, et al. The Effect of Lumbar Spinal Muscle on Spinal Sagittal Alignment: Evaluating Muscle Quantity and Quality. Neurosurgery. 2016;79:847-55.

18. Bach K, Ford J, Foley R, Januszewski J, Murtagh R, Decker S, et al. Morphometric Analysis of Lumbar Intervertebral Disc Height: An Imaging Study. World neurosurgery. 2019;124:e106-18.

19. Crawford RJ, Filli L, Elliott JM, Nanz D, Fischer MA, Marcon M, et al. Age- and Level-Dependence of Fatty Infiltration in Lumbar Paravertebral Muscles of Healthy Volunteers. AJNR Am J Neuroradiol. 2016;37:742-8.

20. Singh DKA, Bailey M, Lee R. Decline in lumbar extensor muscle strength the older adults: correlation with age, gender and spine morphology. BMC Musculoskelet Disord. 2013;14:215.

21. Shahidi B, Parra CL, Berry DB, Hubbard JC, Gombatto S, Zlomislic V, et al. Contribution of Lumbar Spine Pathology and Age to Paraspinal Muscle Size and Fatty Infiltration. Spine. 2017:42:616-23.

22. Yanik B, Keyik B, Conkbayir I. Fatty degeneration of multifidus muscle in patients with chronic low back pain and in asymptomatic volunteers: quantification with chemical shift magnetic resonance imaging. Skeletal Radiol. 2013;42:771-8.

23. Belavý DL, Armbrecht G, Richardson CA, Felsenberg D, Hides JA. Muscle Atrophy and Changes in Spinal Morphology: Is the Lumbar Spine Vulnerable After Prolonged Bed-Rest? Spine. 2011:36:137-45.

24. He K, Head J, Mouchtouris N, Hines K, Shea P, Schmidt R, et al. The Implications of Paraspinal Muscle Atrophy in Low Back Pain, Thoracolumbar Pathology, and Clinical Outcomes After Spine Surgery: A Review of the Literature. Global Spine Journal. 2019. https://doi.org/10.1177/ 2192568219879087

25. Goutallier D, Postel JM, Bernageau J, Lavau L, Voisin MC. Fatty muscle degeneration in cuff ruptures. Pre- and postoperative evaluation by CT scan. Clin Orthop Relat Res. 1994:78-83.

26. Hildebrandt M, Fankhauser G, Meichtry A, Luomajoki H. Correlation between lumbar dysfunction and fat infiltration in lumbar multifidus muscles in patients with low back pain. BMC Musculoskeletal Disorders. 2017:18:12

27. Harms J, Rolinger H. A one-stager procedure in operative treatment of spondylolistheses: dorsal traction-reposition and anterior fusion (author's transl). Z Orthop Ihre Grenzgeb. 1982;120:343-7.
28. Sakeb N, Ahsan K. Comparison of the early results of transforaminal lumbar interbody fusion and posterior lumbar interbody fusion in symptomatic lumbar instability. Indian J Orthop. 2013;47:255-63.

29. Young $S$, Veerapen $\mathrm{R}, \mathrm{O}$ 'Laoire SA. Relief of lumbar canal stenosis using multilevel subarticular fenestrations as an alternative to wide laminectomy: preliminary report. Neurosurgery. 1988;23:628-33.

30. Wiltse LL. The paraspinal sacrospinalis-splitting approach to the lumbar spine. Clin Orthop Relat Res. 1973:48-57.

31. Jiang XZ, Tian W, Liu B, Li Q, Zhang GL, Hu L, et al. Comparison of a paraspinal approach with a percutaneous approach in the treatment of thoracolumbar burst fractures with posterior ligamentous complex injury: a prospective randomized controlled trial. J Int Med Res. 2012;40:1343-56.

32. Foley KT, Lefkowitz MA. Advances in minimally invasive spine surgery. Clin Neurosurg. 2002;49:499-517.

33. Foley KT, Holly LT, Schwender JD. Minimally invasive lumbar fusion. Spine. 2003;28(15 Suppl):S26-35.

34. Zhao Y, Liang Y, Mao K. Radiographic and clinical outcomes following MISTLIF in patients with adult lumbar degenerative scoliosis. J Orthop Surg Res. 2018;13:93.

35. Tan JH, Liu G, Ng R, Kumar N, Wong H-K, Liu G. Is MIS-TLIF superior to open TLIF in obese patients?: A systematic review and meta-analysis. Eur Spine J. 2018:27:1877-86.

36. Hu Z-J, Zhang J-F, Xu W-B, Zhao F-D, Wang J-Y, Fan S-W, et al. Effect of pure muscle retraction on multifidus injury and atrophy after posterior lumbar spine surgery with 24 weeks observation in a rabbit model. Eur Spine J. 2017:26:210-20.

\section{Publisher's Note}

Springer Nature remains neutral with regard to jurisdictional claims in published maps and institutional affiliations.

Ready to submit your research? Choose BMC and benefit from:

- fast, convenient online submission

- thorough peer review by experienced researchers in your field

- rapid publication on acceptance

- support for research data, including large and complex data types

- gold Open Access which fosters wider collaboration and increased citations

- maximum visibility for your research: over $100 \mathrm{M}$ website views per year

At BMC, research is always in progress.

Learn more biomedcentral.com/submission 